\title{
Experiências de adubação mineral e orgânica com Capim Kikuyu (Pennisetum clandestinum Hochst.)
}

T. COURY, A. P. TORRES e G. RANZANI

E. S. A. "Luiz de Queiroz", da Universidade de S. Paulo

Tese apresentada ao II Congresso Pan Americano de Agronomia em Abril de 1953. Piracicaba, E. S. Paulo.

14a. Secção Técnica Científica: - Pastagens e Plantas Forrageiras

\section{INDICE}

$\begin{array}{lllllllllll}1-\text { Introdução } & \ldots & \ldots & \ldots & \ldots & \ldots & \ldots & \ldots & \ldots & \ldots & \ldots\end{array}$

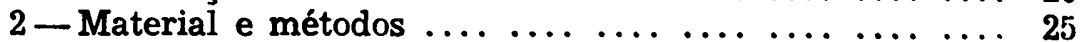

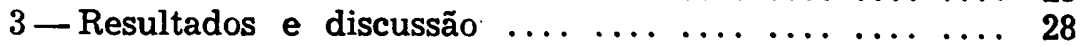

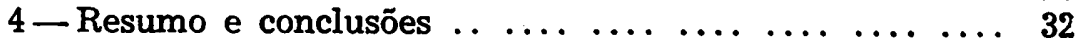

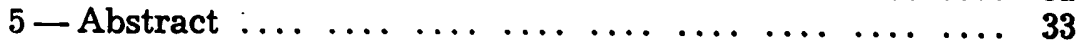

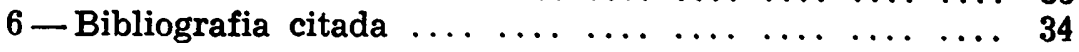




\section{INTRODUÇĀO}

\subsection{Sinonímia, Botânica, Distribuição Geográfica}

\subsubsection{Sinonimia}

O capim de Kikuyú, ordinàriamente identificado como Pennisetum clandestinum Huchst., foi descoberto posteriormente por LEEKE como uma variedade do capim ou paínço da Abissinia, Pennisetum longistylum Hochst., ou seja Pennisetum longistylum, var. clandestinum, pela forma uculta de suas inflorescências.

Desconhecemos qualquer outro nome vulgar, em todos os paises em que foi introduzido. Entre nós modificou-se um pouco sua pronúncia entre os práticos, que passaram a chamá-lo "Quicúio".

\subsubsection{Botânica}

E' uma Gramínea perene atingindo até $1 \mathrm{~m}$ de altura, mais comumente $50 \mathrm{~cm}$, de colmos finos, ôcos, glabros, tenros, de entrenós curtos; eretos ou decumbentes; as fulhas são estreitas $(5 \mathrm{~mm})$, de comprimento variável $(10-30 \mathrm{~cm})$, alternas, invaginantes, cobertas de pêlos curtos, finos, mais frequentes na página dorsal. Possui ainda colmos reptantes e rizómas.

As inflorescências axilares ou terminais, são pouco nítidas, saindo da base da folha, geralmente com 2 a 4 espiguetas, cada uma com 2 flores, a inferior aboriada, quase completamente escondida na bainha. Em Piracicaba floresce raramente no outono, em gramados "judiados" (condições desfavoráveis de vegetação). Nas regiões altas e no Sul do País floresce e sementa com facilidade (OTERO, 1946).

EDWARDS, citado por OTERO (1946), admite três variedades ou ecotipos distintos: Kabete, Molo e Rongai. Este autor identificou a variedade introduzida no Brasil como sendo a Kabete.

\subsubsection{Distribuição Geográfica}

Originária dos planaltos do Território de Kênia, acha-se provàvelmente difundida em tôda a Africa, citando-se o Marrocos, Congo Belga, Transval, Uganda, Abissínia, Tanganika, Saára. Foi levado para a Austrália e quase todos os paises tropicais e subtropicais da América. Foi introduzido nos Estados Unidos, em diversas regiões centrais americanas e da América do Sul.

No Brasil está adatado aos Estados do Centro e Sul, ou sejam, Minas, Mato Grosso, Rio de Janeiro, São Paulo, Paraná, 
Santa Catarina e Rio Grande do Sul, sendo opinião de O TeliO (1946) não medrar bem no Norte e Nordeste.

\subsubsection{Habitat}

De acôrdo com o mesmo autor que vimos de citar, que foi quem mais estudou esta Gramínea neste país, as condições climatéricas favoráveis ao Kikuyú são: "temperaluras relativamente baixas e teor elevado em umidade do ar, aumentado pelas constantes neblinas; o regime de chuvas bem distribuidas durante o ano, atingindo 1.000 a $1.500 \mathrm{~mm}$; temperaturas médias de 13 a $18^{\circ} \mathrm{C}$.". Estas condições não são gəralmente encontradas no planalto paulista, entretanto encontram-se microclimas favoráveis como na serra da Manticiueira, arredores de S. Paulo, e outros lugares, onde o desenvolvimento dessa Gramínea é excepcicnal. Em S. Paulo não se observou dano pela geada, porém no Rio Grande do Sul e Paraná chega a ser "queimado" (OTERO, 1946). Resiste também às temperaturas altas, às secas e às inundações.

A textura do solo parece não ter tanta importância para o Kikuyú como a fertilidade, notadamente a riqueza em humus.

\subsection{Importância como Forrageira}

Em nossa opinião tem-se exagerado um pouco, no país, a importância do Pennisetum clandestinum como forrageira, salvo em certas regiões do Sul, onde se encontram pastagens de relativa importância. Em boas condições suporta 2,5 cabeças por hectare o ano todo, sendo portanto uma excelente forrageira. Entretanto é uma planta extremamenie exigente e exgotante. Em terras pobres ou de mediana fertilidade, após alguns cortes ou pastoreio, amarela, definha e torna-se suceptível a doenças. Uma renovação pode ser efetuada por meic de arações, da queima, mas os efeitos não são duradouros. Simples escarificações não deram resultados notáveis, pelo menos em terras "pesadas". A única maneira de mantê-lo em bom "stand" é pela adubação orgânica, principalmente com esterco de curral. Já em Kenia observou-se que "quando exgotada a matéria orgânica do solo, o Kikuyú tendia a desaparecer. Não obstante, obtivemos resultados apreciáveis pela calagem, seguida de aração, em terra roxa, cansada.

Tivemos igualmente ocasião de fazer feno dessa Gramínea, o qual não foi apreciado pelos equinos. Estudos de palatabilidade de forrageiras realizados por MONTEIRO e TORRES 
(1954), revelaram ser esta uma das espécies mais impalatáveis que possuimos.

Como pastagem para galinhas, embora comumente usado nesta região, não nos pareceu recomendável, a menos que associado ao Cynodon dactylon (TORRES e PIEDADE, 1945). Para perús, entretanto, revelou-se um bom prado, sendo pastado de maneira homogênea. Seu emprêgo como pastagem para suinos pareceu-nos bastante satisfatório, como tivemos oportunidade de observar na Fazenda Experimental de Canchim e outros lugares, o que é justificável pela sua capacidade de recuperação, onde a matéria orgânica de abundantes dejeções (urina e fezes), são constantemente disseminados.

Para os bovinos, tivemos oportunidade de ver alguns piquetes bem formados, de pequena extensão, para a criação de bezerros, devidamente estercados, apresentando excelente "stand". Em pastagens extensas de criação, em terras pobres (campos de Itapetininga) êle tem se propagado com relativa rapidez, mas sua capacidade de suporte não chega a se comparar a outros capins mais produtivos.

Disso tudo concluimos que o Kikuyú ainda nãu teve uma ampla aceitação entre os criadores, prestando-se principalmente para a formação de pequenos pastos para suinos, bezerros e perús, prèviamente bem estercados, casos em que pode competir com outras Gramíneas importantes.

Em nosso ponto de vista constitui uma vantagem o fato dessa Gramínea não ser bem adaptada às nossas condições gerais (TORRES, 1954), porque onde tal fato acontece êle constitui uma praga muito séria e difícil de eliminar. Mesmo onde vai muito mal, quando carpido, rebrota com certo vigor, por várias vezes, só sendo eliminado com relativa facilidade em concorrência com outras culturas mais agressivas, que o abafem. Nos Estados Unidos (Sul da California, e na Costa do Golfo), onde foi introduzido, é considerado uma praga tão temível, como a Grama de Castela (Panicum repens) o é nêste país. Esste caracter invasor foi observado por um nosso colega na serra da Bocaina, onde essa Gramínea invade tudo, tornando-se pràticamente impossível de exterminar.

No Hawaii é considerado ao mesmo tempo uma forrageira preciosa e uma das pragas mais temiveis.

Possui, contudo, apreciáveis qualidades :

1. - resistência ao pisoteio;

2. - protege bem o solo contra a erosão;

3. - rebrota ràpidamente; 
4. - concorre bem com as ervas más, sendo fácil mantê-lo despraguejado;

5. - suporta algumas consociações;

6. - tem bôa capacidade de suporte quando a terra é fértil;

7. - é um dos poucos capins que se mantém verde durante o inverno sêco de S. Paulo;

8. - não se torna tão fibroso na sêca como outros capins;

9. - tem boa composição nutritiva;

10. - quanto mais pastado melhor.

Em contraste podemos apontar como defeitos:

1. - poder constituir uma praga séria;

2. - sua palatabilidade muito baixa, sendo bem pastado só em prados puros;

3. - não dar feno apreciado;

4. - ser muito exigente, não produzindo em terra fraca onde não dispensa adubação orgânica;

5. - ser muito sujeito a doenças e pragas, sobretudo em terra fraca;

6. - em virtude dêsses defeitos não se presta para pastagens extensas, mas apenas para piquêtes ou potreiros.

\subsection{Composiçāo e Valor Nutritivo}

KOK e cols. (1946) estudaram a composição e valor nutritivo do feno de Kikuyú novo, tendo obtido os seguintes resultados :

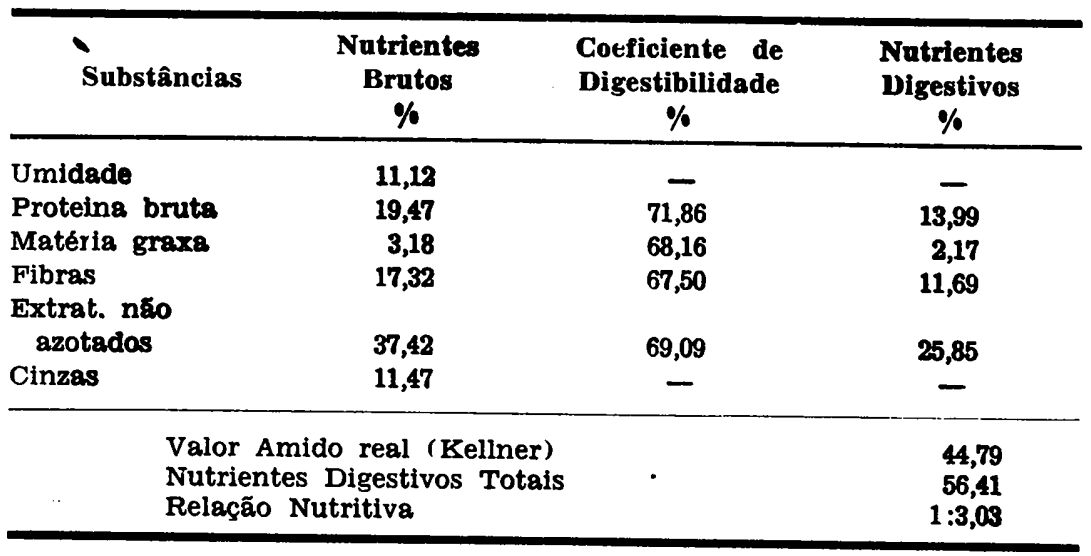


Estes valores superaram o de feno de dez Gramíneas e duas Leguminosas ensaiadas na mesma ocasião e são equivalentes aos obtidos para feno de alfafa, o que deu margem a uma larga propaganda do Kikuyú como substituto da rainha das forrageiras.

OTERO (1946) apresenta dados de análises na Colombia, Hawaii, Uruguay, Africa do Sul, Australia, Rodesia e Brasil (São Paulo e Rio) que confirmam uma alta percentagem de proteina nas plantas novas, o que aliás se verifica em tốdas as Gramineas.

Fiesultados muito interessantes foram por nós obtidos, e se acham expressos no Quadro VI dêste trabalho onde se pode observar a importância decisiva da adubação na composição desta forrageira.

\subsection{Necessidade de Adubação das Pastagens}

As terras do Estado de São Paulo, anteriormente usadas em culturas, são geralmente pobres, esgotadas ou cansadas) carentes de matéria orgânica e ainda de N, P, K e Ca.

E' sabido que as Gramineas reagem muito favoràvelmente à adubação orgânica e mesmo ao $\mathrm{N}$ mineral. Em São Paulo observa-se na maicria das terras uma reação ao emprêgo de $P$ que se encontra no minimo. Em casus excepcionais (terras arenosas) o $\mathrm{K}$ pode encontrar-se também no mínimo.

A influência da adubação sôbre a qualidade da forragem afetando o próprio estado de saúde do animal tem sido demonstrada por diversos autores.

O valor nutritivo das forrageiras, até certo ponto, é nnuito influenciado pela fertilidade do solo, mormente pelo seu conteúdo em minerais assimiláveis, já se tendo constatado para o caso das Gramíneas, notável elevação de seu teor em proteina bruta pela adição de $\mathrm{N}$ ou matéria orgânica ao solu. $\mathrm{O}$ nivel de elevação dêsse teor é limitado entretanto para cada espécie, tendo-se verificado que para Gramíneas pouco exigentes não há apreciável elevação do seu conteúdo em proteina, ao contrário do que se verifica com as espécies mais exigentes.

Fenômeno semelhante ocorre com o P2O5, K2O, e outros elementos, cujo teor aumenta nas plantas proporcionalmente às adubações, de conformidade com a evigência genética ou variedade. 
Resulta que as pastagens adubadas, não só fornecem maior volume de forragem, como de melhor qualidade e de maior valor nutritivo.

\section{MATERIAL E MÉTODOS}

Tratando-se de forrageira muito exgotante, julgamos interessante instalar um ensaio para verificar as exigências do $\mathrm{Ki}$ kuyú quanto aos elementos nutritivos do solo e dos fertilizantes incorporados, mineral e orgânico. O ensaio de campo foi instalado em terras da 2a. Seção de Zuotecnia, da E. S. A. "Luiz de Queiroz", em Piracicaba.

\subsection{Solo}

O solo utilizado no referido experimento apresentou os seguintes resultados analíticos:

Análises das terras do ensaio - Quadro I

\begin{tabular}{|c|c|c|c|c|c|c|c|c|c|c|}
\hline \multirow{2}{*}{ Blocos } & \multicolumn{7}{|c|}{ ANÁLISE QUIMICA } & \multicolumn{3}{|c|}{$\begin{array}{l}\text { Analles } \\
\text { fisico-mecânios } \\
\text { (Bouyoucos) }\end{array}$} \\
\hline & $\begin{array}{l}\text { Extra } \\
\mathrm{P}_{20} \\
0 / 0\end{array}$ & $\mid \mathrm{CaO}=$ & $\begin{array}{l}\text { idrico a } \\
\mid \mathrm{K} 20 \%\end{array}$ & $\begin{array}{c}20 \% \\
\mathrm{MgO} \\
0 \%\end{array}$ & NO $\%$ & $\begin{array}{l}\text { Mat. } \\
\text { org. } \\
\text { o/0 }\end{array}$ & $\begin{array}{c}\text { Indice } \\
\mathrm{pH}\end{array}$ & $\begin{array}{l}\text { Areia } \\
\text { total } \\
0 / 0\end{array}$ & $\begin{array}{c}\text { Argila } \\
0 / 0\end{array}$ & $\begin{array}{l}\text { Lodo } \\
0 / 0\end{array}$ \\
\hline $\mathbf{A}$ & 0,024 & 0,076 & 0,081 & 0,024 & 0,062 & 1,409 & 5,1 & 46 & 36 & 18 \\
\hline B & 0,027 & 0,078 & 0,097 & 0,054 & 0,059 & 1,812 & 5,3 & 38 & 41 & 21 \\
\hline C & 0,025 & 0,056 & 0,102 & 0,036 & 0,056 & 1,746 & 5,2 & 45 & 36 & 18 \\
\hline $\mathbf{D}$ & 0,023 & 0,070 & 0,093 & 0,052 & 0,064 & 1,940 & 5,1 & 35 & 45 & 20 \\
\hline $\begin{array}{l}\text { Interpreter } \\
\text { çăo }\end{array}$ & pobre & regular & rogular & regular : & pobre & pobre & $\begin{array}{l}\text { acidez } \\
\text { módia }\end{array}$ & $\begin{array}{r}\text { Obs. : } \\
\text { solo }\end{array}$ & $\begin{array}{l}\text { Tra } \\
\text { argil }\end{array}$ & $\begin{array}{l}e \quad d e \\
\text { licoso }\end{array}$ \\
\hline
\end{tabular}

A análise química foi feita pelos métodos em uso na $2 a$. Cadeira (COURY, 1937), e a análise física pelo método de Bouyoucos (MELLO MORAES e COURY, 1936).

Éste solo, apesar de dotado de bôas propriedades físicas, é pobre em matéria orgânica, nitrogênio e fósforo. A amostragem foi feita na camada superficial até a profundidade de $30 \mathrm{~cm}$; cada bloco forneceu 8 amostras, ou seja, uma de cada canteiro e uma vez bem misturadas se prestaram como amostra média representativa do bloco. 


\subsection{Ensaio de Campo}

O delineamento escolhido foi o de blocos ao acaso, com 8 tratamentos e 4 repetições (blocos A-B - C - D) num total de 32 canteiros; cada canteiro com a área de $48,5 \mathrm{~m} 2(5 \mathrm{~m} \times 9,7 \mathrm{~m})$ e bordadura de $1 \mathrm{~m}$.

Esquema experimental - Quadro II

\begin{tabular}{|c|c|c|c|}
\hline 1 & 5 & 1 & 8 \\
\hline 2 & 6 & 4 & 3 \\
\hline 3 & $A$ & 5 & 6 \\
\hline 4 & 8 & 2 & 7 \\
\hline 7 & 1 & 3 & 8 \\
\hline 6 & 3 & 4 & 2 \\
\hline 5 & 8 & 1 & 7 \\
\hline 2 & 4 & 5 & 6 \\
\hline
\end{tabular}

\subsubsection{Tratamentos}
n. $1-\mathrm{N}-\mathrm{P}-\mathrm{-K}-\mathrm{Ca}-\mathrm{-Mg}$
n. $2-\mathrm{N}-\mathrm{P}-\mathrm{K}-\mathrm{-Ca}-\mathrm{O}$
n. $3-\mathrm{N}-\mathrm{-P}-\mathrm{K}-\mathrm{-O}-\mathrm{-Mg}$
n. $4-\mathrm{O}-\mathrm{-P}-\mathrm{-K}-\mathrm{-Ca}-\mathrm{-Mg}$
n. $5-\mathrm{N}-\mathrm{O}-\mathrm{-K}-\mathrm{Ca}-\mathrm{Mg}$
n. 6 - N--P--O--Ca--Mg
n. 7-Matéria orgânica
n. 8-Testemunha

Adubação

- Mineral completa

- Sem Mg

- Sem Ca

- Sem N

- Sem P

- Sem K

- Estêrco de curral

- Sem nada 


\subsubsection{Adubos e quantidades}

Os adubos empregados foram os seguintes:

Sulfato de amônio com $20,5 \%$ de $\mathrm{N}$ amoniacal

Salitre do Chile com $15,5 \%$ de $\mathrm{N}$ nítrico (em cobertura)

Farinha de ossos degelatinada com $30 \%$ de P2O5 total

Superfosfato americano com $20 \%$ de $\mathrm{P} 2 \mathrm{O} 5$ solúvel

Cloreto de potássio com $50 \%$ de $\mathrm{K} 2 \mathrm{O}$ solúvel

Sambaquís com $43 \%$ de $\mathrm{CaO}$ cobertura)

Sulfato de magnésio puro com $33 \%$ de $\mathrm{MgO}$ solúvel (em

A adubação empregada obedeceu a seguinte relação:

$$
\begin{aligned}
& \mathrm{N}-\mathrm{P} 2 \mathrm{O} 5-\mathrm{K} 2 \mathrm{O}-\mathrm{CaO}-\mathrm{MgO} \\
& 1-2-1-1=0,2
\end{aligned}
$$

A relação entre formas de $\mathrm{N}$ e $\mathrm{P} 2 \mathrm{O} 5$ foi a seguinte :

$$
\begin{aligned}
& \mathrm{NH}^{4+}-\mathrm{NO}^{3-}-\mathrm{P}^{2} \mathrm{O}^{5} \text { far. }-\mathrm{P}^{2} \mathrm{O}^{5} \text { super } \\
& 4 / 5-1 / 5-3 / 5-3 / 5
\end{aligned}
$$

Os adubos salitre e sulfato de magnésio foram incorporados em cobertura, 40 dias após o plantio; os demais adubos minerais foram distribuidos pouco antes do plantío, como adubação fundamental; a adubação mineral foi feita na base de 2 tons. por alqueire paulista e a adubação orgânica (estêrco de curral bem curtido) na base de 60 tons. por ha., ou seja $6 \mathrm{~kg}$ por $\mathrm{m} 2$.

A quantidade de adubos empregada por canteiro se acha no quadro III.

$$
\text { Quantidade de adubos - Quadro III }
$$

\begin{tabular}{lccc}
\hline Pêso total de fertilizante & $\begin{array}{c}\text { Elemento } \\
\text { util }\end{array}$ & Total & Relação \\
\hline $1.000 \mathrm{~g}$ de farinha de ossos & $300 \mathrm{~g}$ & & \\
$1.000 \mathrm{~g}$ de superfosfato & $200 \mathrm{~g}$ & $500 \mathrm{~g}$ de P2O & 2 \\
$1.000 \mathrm{~g}$ de sulfato de amónio & $200 \mathrm{~g}$ & & \\
$350 \mathrm{~g}$ de salitre do Chile & $50 \mathrm{~g}$ & $550 \mathrm{~g}$ de $\mathrm{N}$ & 1 \\
$500 \mathrm{~g}$ de cloreto de potássio & $250 \mathrm{~g}$ & $250 \mathrm{~g}$ de $\mathrm{K2O}$ & 1 \\
$600 \mathrm{~g}$ de sambaquís & $250 \mathrm{~g}$ & ¿́50g de CaO & $\mathrm{J}$ \\
$150 \mathrm{~g}$ de sulfato de magnésio & $50 \mathrm{~g}$ & $50 \mathrm{~g}$ de $\mathrm{MgO}$ & $\mathbf{0 , 2}$ \\
$300 \mathrm{Kg}$ de estêrco de curral & - & - & - \\
\hline
\end{tabular}




\subsubsection{Ocorrências}

Foram procedidas por 4 vêzes a extirpação de hervas más e outras Gramíneas, 2 cortes e 1 penteamento no decorrer do ensaio; houve bôa chuva após o plantío e uma fraca 65 dias após, escasseando a seguir, só chovendo bem novamente após o $1^{\circ}$. corte.

\subsubsection{Observações}

O tratamento n. 7 (matéria orgânica) revelou-se sempre superior, principalmente na broiação, o que se justifica pela maior retenção dágua determinada peia matéria oryânıca incorporada ao solo maximé levando-se em conta a escassez de chuvas nos primeiros meses; também o desenvolvimento vegetaiıvo, largura das folhas, cór verde intensa, foram atributos que caracterizaram melhor êsse tratamento em cunfronto com os demais.

\section{RESULTADOS E DISCUSSÃO}

3.1. No quadro IV estão as produções obtidas por canteiro, em quilogramas, a média, o total de cada tratamento e a ordem de classificação (total dos 2 cortes havidos), além dos totais dos blocos e total geral.

\section{Produção - Quadro IV}

\begin{tabular}{|c|c|c|c|c|c|c|c|}
\hline 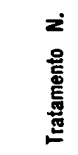 & $\begin{array}{r}a \\
.8 \\
-\frac{8}{0}\end{array}$ & $\begin{array}{l}\infty \\
\frac{8}{0} \\
\frac{0}{\infty}\end{array}$ & $\begin{array}{l}0 \\
8 \\
\frac{8}{0}\end{array}$ & 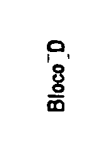 & 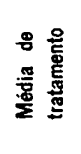 & 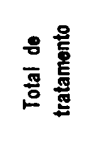 & 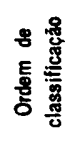 \\
\hline 1 & 23,9 & 25,0 & 27,4 & 30,8 & 26,8 & 107,1 & $2 \circ$. \\
\hline 2 & 19,3 & 20.1 & 21,2 & 21,2 & 20,4 & 81,8 & $4^{\circ}$. \\
\hline 3 & 23,4 & 21,3 & 28,2 & 24,3 & 24,3 & 97,2 & $3^{\circ}$. \\
\hline 4 & 14,1 & 10,8 & 11,9 & 9,7 & 11,6 & 46,5 & $7^{\circ}$. \\
\hline 5 & 13,2 & 15,1 & 14,0 & 13,3 & 13,9 & 55,6 & $6^{\circ}$ \\
\hline 6 & 20,0 & 20,1 & 22,5 & 18,2 & 20,2 & 80,8 & $5^{\circ}$ \\
\hline 7 & 61,3 & 58,7 & 57,5 & 52,1 & 54,9 & 219,6 & $1^{\circ}$ \\
\hline 8 & 7,8 & 9,2 & 8,3 & 8,4 & 8,4 & 33,7 & $8^{\circ}$. \\
\hline $\begin{array}{c}\text { Totais } \\
\text { dos } \\
\text { blocos }\end{array}$ & 173,0 & 180,3 & 191,0 & 178,0 & - & 722,3 & $\begin{array}{l}\text { Total } \\
\text { goral }\end{array}$ \\
\hline
\end{tabular}


3.2 A análise de variância se acha resumida no Quadro V.

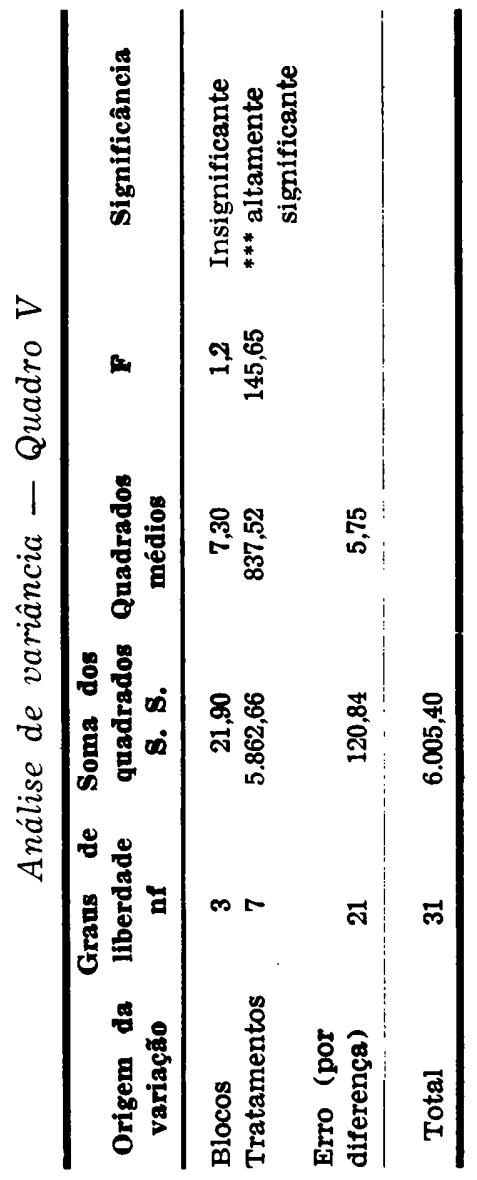

Procedeu-se ainda, a comparação entre os tratamentos pelo emprêgo do teste $t$ e verificou-se o seguinte: (1) superioridade marcante do tratamento n. 7 sôbre os demais; (2) superiodade do n. 1 sôbre os ns. 2, 3, 4, 5, 6 e 8; (3) do n. 3 sôbre os ns. 2, 4, 5, 6 e 8; (4) dos ns. 2 e 6 (não houve diferença estatística entre ambos) sôbre os ns. 4,5 e 8 ; (5) do n. 5 sôbre os ns. 4 e 8 e (6) finalmente do n. 4 sôbre o n. 8.

3.3 Fez-se também coleta de amostras do capim Kikuyú, 4 amostras de cada tratamento, colhidas nos blocos A, B, C e D. Os resultados expressos no quadro VI se referem a média 


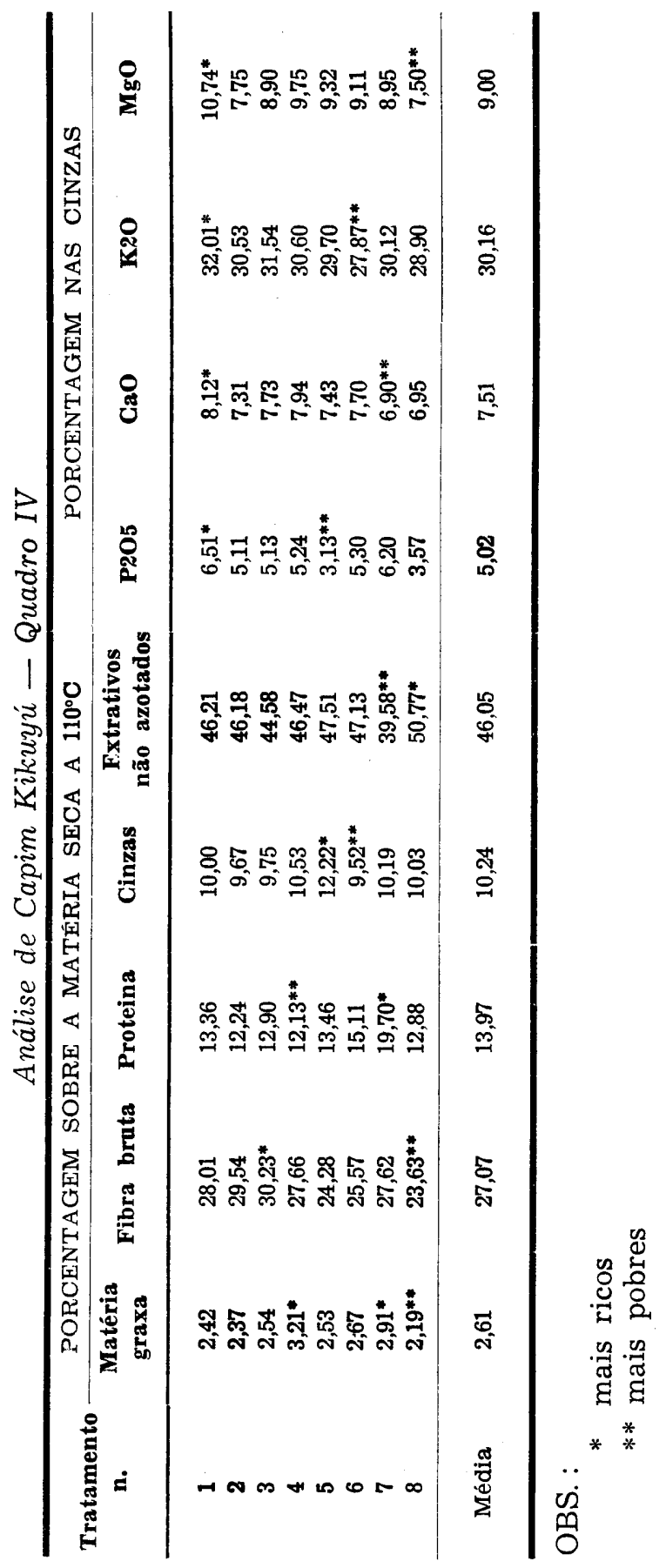


de 4 determinações, em porcentagem sôbre a matéria sêca a $110^{\circ} \mathrm{C}$ (matéria graxa, fibra bruta, proteina, cinzas e extrativos não azotados) e em porcentagem nas cinzas ( $\mathrm{P2O}, \mathrm{CaO}$, $\mathrm{K} 2 \mathrm{O}$ e $\mathrm{MgO}$ ). Tôdas as análises foram feitas pelos métodos do A. O. A. C. (1945).

\subsubsection{Comentário sôbre as análises do capim}

A análise dos resultados da composição química da forragem obtida em cada tratamento foi muito interessante quando comparada à média de todos as análises.

(Gr $=$ graxa, $\mathrm{Fb}=$ fibra bruta, $\mathrm{Pr}=$ proteina bruta, $\mathrm{Cs}=$ cinzas, ENA $=$ extrativos não azotados).

Tratamento n. 1 - Adubação mineral completa. Deu a forragem mais rica em $\mathrm{P}, \mathrm{K}, \mathrm{Ca}$ e $\mathrm{Mg}$. Os teores de nutrientes brutos e cinzas se aproximam da média.

Tratamento $n$. 2 - Adubação mineral sern $M g$. Verificou-se baixo teor de $\mathrm{Mg}$ e decréscimo em $\mathrm{Gr}, \mathrm{Pr}, \mathrm{Cs}$ e aumento da $\mathrm{Fb}$.

Tratamento n. 3 - Adubação sem Ca. Maior teor de K. Teor de $\mathrm{Ca}$ equivalente à média dos tratamentos. Foi o que deu maior porcentagem de $\mathrm{Fb}$ e houve diminuição dos nutrientes mais valiosos: $G r, \operatorname{Pr}, E N A$ e $C s$.

Tratamento n. 4 Adubação mineral sem N. Deu o mais alto teor em $\mathrm{Gr}$ e o mais baixo em $\mathrm{Pr}$. ...

Tratamento n. 5 - Adubação mineral sem $P$. Deu o mais alto teor de Cs e o mais baixo em $\mathrm{P} 2 \mathrm{O}$, sendo também pobre em $\mathrm{Fb}$ e rico em $E N A$.

Tratamento n. 6 - Adubação mineral sem $K$. Deu a mais pobre em $\mathrm{K} 2 \mathrm{O}$ e $\mathrm{Cs}$; um teor relativamente alto de $\mathrm{Pr}$ e baixo em Ca. O K2O é o componente que enira em maior porcentagem nas cinzas.

Tratamento n. 7 - Adubação orgânica. Estêrco de curral. Deu uma porcentagem de $\mathrm{Pr}$ extremamente alta $(19,70)$, alto teor de $\mathrm{Gr}$ e $\mathrm{P} 2 \mathrm{O5}$ e o mais baixo em ENA. O teor em Ca foi o mais baixo verificado.

Tratamento n. 8 - Testemunha - Sem nada. Apresentaram o mais baixo teor em $\mathrm{Gr}, \mathrm{Fb}$, e $\mathrm{MgO}$. Os teores de $\mathrm{Pr}, \mathrm{Cs}$, $\mathrm{P} 2 \mathrm{O} 5, \mathrm{CaO}, \mathrm{K} 2 \mathrm{O}$ foram baixos, e o de $\mathrm{Mg}$ extremamente baixo. 
Esses resultados analíticos corresponderam à expectativa e dêles também se conclue ser o solo usado deficiente em todos os elementos, e o Kikuyú uma planta de grande sensibilidade (exigente) às adubações.

\section{RESUMO E CONCLUSÕES}

O Kikuyú é sem dúvida uma forragem bastante recomendada para bovinos, equinos e suinos; sua composição química é muito semelhante a da alfafa, quando novo e proveniente de solo rico, daí a razão dêste trabalho a que as Secções de Avicultura (Zootecnia II) e Química Agrícola se propuzeram a fazer. Foi feito um ensaio de campo, em canteiros de $50 \mathrm{~m} 2$, blocos ao acaso com 8 tratamentos, a saber:

$1 \mathrm{~N}-\mathrm{P}-\mathrm{K}-\mathrm{Ca}-\mathrm{Mg}$ - Adubação completa

$2 \mathrm{~N}-\mathrm{P}-\mathrm{K}-\mathrm{Ca}-\mathrm{Sem} \mathrm{Mg}$

$3 \mathrm{~N}-\mathrm{P}-\mathrm{K}-\mathrm{Mg}-\mathrm{Sem} \mathrm{Ca}$

$4-\mathrm{P}-\mathrm{K}-\mathrm{Ca}-\mathrm{Mg}-\mathrm{Sem} \mathrm{N}$

$5 \mathrm{~N}-\mathrm{K}-\mathrm{Ca}-\mathrm{Mg}-\mathrm{Sem} \mathrm{P}$

$6 \mathrm{~N}-\mathrm{P}-\mathrm{Ca}-\mathrm{Mg}-\mathrm{Sem} \mathrm{K}$

7 Matéria orgânica sem adubação mineral

8 Testemunha sem nada

$\mathrm{O} \mathrm{N}$ foi aplicado nas formas nítrica (em cobertura) e amoniacal, o P2O5 nas formas solúvel de superfosfato e pouco solúvel de farinha de ossos, $\mathrm{K} 2 \mathrm{O}$ na forma de cloreto, $\mathrm{CaO}$ como Sambaquís e $\mathrm{MgO}$ como MgSO4 (em cobertura).

A adubação orgânica foi feita com estêrco de curral bem curtido.

Foi evidente a superioridade do tratamento n. 7 sôbre os demais. Dentre os minerais a falta de $\mathrm{N}$ e P2O5 se fez sentir. Com relação ao testemunha, cuja produção foi ínfima, todos os tratamentos foram sensivelmente superiores. O solo trabalhado é tipo Catanduva barrento, paupérrimo em matéria orgânica, com regular teor em $\mathrm{K} 2 \mathrm{O}, \mathrm{CaO}$ e $\mathrm{MgO}$, pobres em $\mathrm{N}$ e $\mathrm{P} 2 \mathrm{O} 5$.

A análise das forragens dos vários tratamentos revelou:

a) maior teor em proteinas nos tratamentos 7, 6, 5 e 1 na ordem decrescente e o mais pobre, como aliás era esperado, foi o tratamento n. $4(\operatorname{sem~N})$;

b) o tratamento n. 4 foi o mais rico em matéria graxa e com apreciável teor também o n. 7 - o mais pobre foi o testemunha (n. 8); 
c) fibra bruta - mais rica, no 7 e mais pobre, no 8;

d) em relação às cinzas o n. 5 foi o mais rico e o n. 6 (sem $\mathrm{K}$ ) o mais pobre (os extrativos foram determinados por simples diferença dos demais para 100); e

f) elementos minerais das cinzas: geralmente os tratamentos sem determinado elemento mineral deram resultados análíicicos com baixo teor no mesmo, revelando ainda pobreza no solo do ensaio do referido corpo.

$\mathrm{Na}$ produção de masssa, após a matéria orgânica, o $\mathrm{N}$ revelou-se o elemento mais importante, seguido pelo $\mathrm{P} 2 \mathrm{O} 5$, o $\mathrm{K} 2 \mathrm{O}$, - $\mathrm{IMg}$, e por fim o Ca.

Concluem os autores por aconselhar: adubações orgânicas na formação e renovação de pastagens de Kikuyú com estêrco e quando não possível o uso de adubo verde ou composto em substituição àquele.

\section{ABSTRACT}

Kikuio grass (Pennisetum clandestinum Hochst) is beyond any doubi, a pasture very important for farm animals; since its chemical compusition is very similar to that of alfalfa, the present field irial was carried out; a randomized block design with 8 treaiments was selecied as follows:

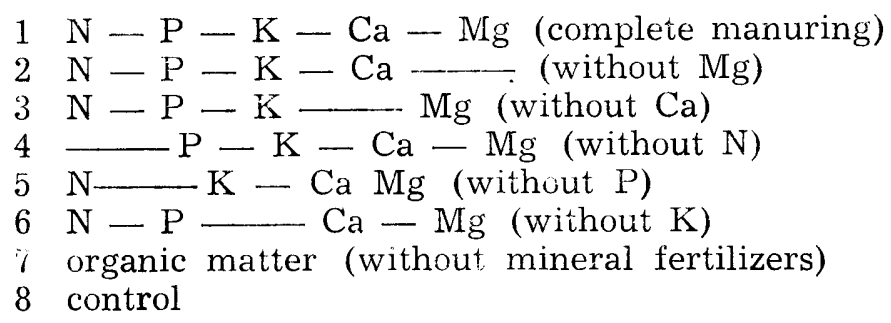

Nitrogen was applied as NaNO3 (topdressed) and as ammonium sulfate; $\mathrm{P} 2 \mathrm{O} 5$ was given as superphosphate associated to bonemeal; $\mathrm{K} 2 \mathrm{O}$ was applied as muriate, $\mathrm{CaO}$ as "sambaquis" (oyster shells); $\mathrm{MgO}$ was given as MgSO4 (topdressed). The source of organic matter was farmyard manure.

As far yields are concerned the following observations were made:

1. treatment $n$. 7 was superior to all others;

2. considering the mineral fertilizers, good responses were due to $\mathrm{N}$ and $\mathrm{P} 2 \mathrm{O} 5$; 
3. the control yield was exceedingly poor, being inferior to all the others treatments;

The chemical analyses revealed that:

1. the protein content decreased accordingly to this order: $7,6,5$ and 1 ; treatment 4 (without $\mathrm{N}$ ) gave the lowest protein content;

2. treatment $\mathrm{n} .4$ produced the highest fat content; treatment no. 7 ranked second; no. 8 gave the lowest fat content;

3. crude fiber : highest - treatment 7 ; lowest - 8;

4. ashes: the ashes content was higher in treatment 5; proprobably because the most abundant element in the ashes is $\mathrm{K}$, the ash content of treatment 6 (no $\mathrm{K}$ ) was very low;

5. non nitrogenous substances (determined by difference) - high in treatment 8 and low in treaimen 7 ;

6. mineral elements in the ashes - the element omitted from a given treatment was very low in the grasses therein obtained; this shows the relative poverty of the soil in that element.

As general remark the Authors suggest the use of farmyard manure in the fertilization of Kikuio grass; farmyard manure could probably substitute wither green manure or compost.

\section{BIBLIOGRAFIA CONSULTADA}

ANDRADE, B. M., 1948 - Formação e Trato das Pastagens. S. I. A. Ministério da Agricultura, Rio de Janeiro, Brasil.

A. O. A. C., 1945 - Official and Tentative Methods of Analysis. 6th Ed. Washington, D. C.

CARR, R. B. and RHOAD, A. O., 1943 - Influence of Lime and Fertilizers on Pasture Establishement at Jeanerette, La., Circ. n. 666. U. S. D. A. Washington, D. C. U. S. A.

CHENEY, H. B., 1940 - Pasture, Improvement and Management. Bull. P8 (New Series) Agr. Exp. St., Iowa State College, Ames, Ia., U. S. A.

COURY, T., 1937 - Apostilas de práticas de Química Agrícola - Mimeogrado.

(DIVERSOS), 1948 - Grass. The Yearbook of Agriculture. U. S. D. A. U. S. Gov. Print. Of., Washington D. C. 
D'UTRA, G. P., 1919 - Estrumes Mistos e "Compostos". Secr. Agr. Ind. e Com. S. Paulo. Serviço de Publicidade. S. Paulo, Brasil.

HITCHCOCK, A. S., 1950 - Manual of the Grasses of the United States, Govern. Print., Washington.

HUGHES, H. D., M. E. HEATH, D. S. METCALFE, 1952 Forages, pp. 724 - Ames, Iowa.

KOK, A. K., L. B. MACHADO e G. L. ROCHA, 1946 - Valor nutritivo de plantas forrageiras, in Bol. Ind. Animal, 8: 3: $18-44$.

LARSEN, LAURITS, 1951 - Fertilizing Grassland. IIème Congres Mondial des Engrais Chimiques, Rome, October.

MELLO MORAES, J. e T. COURY, 1936 - Análises dos Solos - Rev. "O Solo" n. 314.

MONTEIRO, F. P. e A. P. TORRES, 1954 - Contribuição para o estudo da palatabilidade de algumas forrageiras. Tese apresentada ao $2^{\circ}$. Congresso Pan-Americano de Agronomia.

MORRISON, F. B., 1938 - Feeds and Feeding. 20 ${ }^{\circ}$ th Edition, unabridged, The Morrison Publishing Co.

OTERO, J. R., 1946 - O Capim Kikuyú, S. D. A. - 310, 2a. ed., pp. 36. Minist. Agr., Rio de Janeiro.

PENTZ, J. A., 1932 - Agricultural Grasses of South Africa and Management of Their Pastures. - Bull. n. 106. Union of South Africa. Department of Agriculture.

TORRES, A. P. e A. PIEDADE, 1945 - Gramados para Parques avícolas. Nota prévia - Anais da E. S. A. L. Q. U. S. P. - 2: 431-454, Piracicaba.

TORRES, A. P., 1953 - Gramados para Parques Avícolas, II, in São Paulo Avícola, da A. P. A., São Paulo.

TORRES, A. P., 1954 - Agressividade de algumas gramíneas forrageiras da região de Piracicaba. Tese apresentada ao $2^{\circ}$. Congresso Pan-Americano de Agronomia. 
